\title{
Operational and Environmental Efficiencies of Japanese Electric Power Companies from 2003 to 2015: Influence of Market Reform and Fukushima Nuclear Power Accident
}

\author{
Mika Goto ${ }^{1}$ and Toshifumi Takahashi \\ ${ }^{1}$ Innovation Science/Technology and Innovation Management, School of Environment and Society, Tokyo Institute of Technology, \\ 2-12-1 Ookayama, Meguro-ku, Tokyo 152-8552, Japan \\ ${ }^{2}$ Technology and Innovation Management, School of Environment and Society, Tokyo Institute of Technology, \\ 2-12-1 Ookayama, Meguro-ku, Tokyo 152-8552, Japan
}

Correspondence should be addressed to Mika Goto; goto.m.af@m.titech.ac.jp

Received 11 July 2017; Accepted 10 December 2017; Published 31 December 2017

Academic Editor: Nazrul Islam

Copyright (C) 2017 Mika Goto and Toshifumi Takahashi. This is an open access article distributed under the Creative Commons Attribution License, which permits unrestricted use, distribution, and reproduction in any medium, provided the original work is properly cited.

\begin{abstract}
This study measures operational and environmental efficiencies of nine incumbent electric power companies (EPCos) in Japan and examines an influence of market reform and Fukushima nuclear power plant accident on efficiencies using a data set from 2003 to 2015. This study applies output-oriented radial data envelopment analysis (DEA) model to the measurement of efficiencies. Three inputs and three desirable outputs are used for the measurement of operational efficiency, and one undesirable output besides inputs and desirable outputs is used to measure environmental efficiency. EPCos produce not only desirable output, for example, electricity, but also undesirable output, for example, $\mathrm{CO}_{2}$, for their operations. For the measurement of environmental efficiency, this study uses a unique DEA model that assumes occurrence of ecotechnology innovation. The results reveal that environmental efficiency of EPCos is mostly invariant over the period of this study, while operational efficiency decreases in the same period. In addition, the results present that Japanese EPCos make efforts to reduce $\mathrm{CO}_{2}$ emissions by promoting ecotechnology innovation. The Kruskal-Wallis rank sum test indicates differences in operational and environmental efficiencies among EPCos. Such performance differences might become larger as market liberalization advances, which could lead to further structural changes of the industry.
\end{abstract}

\section{Introduction}

Public awareness about environmental protection and sustainable development has been growing globally in recent years. The problems of global warming and climate change in particular have received attention after the Kyoto Protocol was adopted in 1997 and enacted in 2005. Various measures for reducing $\mathrm{CO}_{2}$ emissions produced from human activities have been discussed among participants in the United Nations Framework Convention on Climate Change (UNFCCC). The UNFCCC's Paris Agreement entered into force on November 4, 2016. The agreement's central aim is to strengthen the global response to the threat of climate change by keeping global temperature rises this century well below 2 degrees Celsius compared to preindustrial levels and to pursue efforts to limit the temperature increases even further to 1.5 degrees Celsius. Since any single nation in the world cannot combat global warming and climate change alone, it is necessary for all nations to cooperate to solve the problem.

Improving energy and environmental efficiencies of the electricity generation sector is one of the most important policy agendas toward the sustainable development of the world. In Japan, more than $90 \%$ of $\mathrm{CO}_{2}$ emissions have been produced from various energy uses. Under this situation, the role of the electricity industry in improving energy efficiency and environmental protection has become increasingly important. Indeed, the electricity industry played a key role in reducing $\mathrm{CO}_{2}$ emissions during the first commitment period under the Kyoto Protocol from 2008 to 2012. However, share of $\mathrm{CO}_{2}$ emissions from electricity generation in emissions from total energy use rose in Japan owing to the 
decrease in electricity generation from nuclear power plants and the increase in that from fossil fuel power plants after the Fukushima Daiichi nuclear power plant accident, which occurred after the Great East Japan Earthquake and Tsunami on March 11, 2011. For example, in 2010, $\mathrm{CO}_{2}$ emissions from electricity generation accounted for approximately $38 \%$ of the emissions produced from total energy use in Japan, but rose to approximately $43 \%$ in 2014 . Amid turmoil in Japan's national energy policy and future energy plans after the Fukushima disaster, the country withdrew from the second commitment period of the Kyoto Protocol, because its $\mathrm{CO}_{2}$ reduction plan before the Fukushima accident had largely depended on the planned increase in nuclear power generation. As of June 2017, only five nuclear units are operational among 57 commercial units in total in Japan. As a result, Japan's total $\mathrm{CO}_{2}$ emissions have been increasing since 2011 owing to changes in the generation fuel mix.

Meanwhile, energy market liberalization gained momentum after the Fukushima Daiichi nuclear power plant disaster and the Japanese government has strongly advanced market liberalization. The momentum for the reform was maintained even after the change of administration in December 2012 from Democratic Party of Japan to Liberal Democratic Party. Under the reform process, the retail electricity market was fully liberalized on April 1, 2016. This was the first major change in the electricity market since April 2005, when the medium-sized consumers, each with at least $50 \mathrm{~kW}$ of demand, were given eligibility to choose suppliers under the gradual process of retail market liberalization from large to small consumers. By the measure in 2005, almost twothirds of electricity consumption was opened to competitive suppliers. In addition, Japan's market liberalization plans structural change of the electricity industry in the future. The incumbent electric power companies (EPCos) are currently vertically integrated from generation to retail functions. However, their transmission and distribution network divisions are supposed to be separated from generation and retail divisions by 2020 (an exception is Tokyo EPCo, which had already implemented vertical separation under a holding company (Tokyo Electric Power Co. Holdings, Inc.) in April 2016, prior to the other EPCos).

The purpose of this study is to measure the operational and environmental efficiencies of nine Japanese EPCos applying a data envelopment analysis (DEA) to a data set from 2003 to 2015, and to examine whether efficiency has changed over the period and among the companies. In particular, this study examines the impact of the Fukushima Daiichi nuclear power plant accident on the efficiencies of EPCos, because the occurrence might have influenced not only their operational efficiency but also environmental efficiency on $\mathrm{CO}_{2}$ emissions through changes in their fuel mix. In addition, this study examines whether EPCos have made efforts to improve environmental efficiency by investing in ecotechnology innovation. From the results, this study discusses policy implications for Japan's sustainable development from the perspective of electricity market reform and operations of Japanese EPCos.

\section{Previous Research}

Productivity and efficiency analysis of the electricity industry has long been a popular research issue in production economics and regulatory economics. One reason for its popularity is the government regulation for the electricity industry. The electricity industry was a representative natural monopoly industry until quite recently, and many electric power companies in the world operated vertically integrated businesses from generation to retail. They supplied electricity to consumers who locate in their exclusive supply areas. The governmental regulation was useful to restrict profit-maximizing behavior of natural monopoly firms; however, it was also well known among researchers that " $X$ inefficiency" might arise because of a lack of discipline that would be brought about from market competition [1]. Therefore, assessment of operational efficiency of firms was important for governments to implement effective regulation and improve operational efficiency of natural monopoly firms. Otherwise, inefficient firms could survive by receiving benefits from regulation, as specified by the concept of $X$ inefficiency. In addition, operational data sets on the electricity industry were historically well established and disclosed to the public by regulation. This was another reason for popularity of productivity and efficiency analysis of electricity industry.

However, since the global trend of electricity market reform that began in the 1990s, many countries and regions advanced structural reform of the industry and separated transmission and distribution network sector from generation and retail sectors. The transmission and distribution network sector remains under government regulation, but generation and retail sectors introduced market competition and removed regulation. Under the new framework of electricity industry, productivity and efficiency analysis has two roles. One is the same role before the market reform or an assessment for regulation, and the other is to use the analyzed information for corporate management and policy discussion to improve operational and environmental efficiencies of EPCos and the industry as a whole.

Data envelopment analysis (DEA) is often used for the productivity and efficiency analysis of various decisionmaking units (DMUs), for example, EPCos in this study, since the seminal work of Charnes et al. [2]. Many researchers have developed various types of DEA models and applied them to efficiency assessment. For example, the additive model was first proposed by Charnes et al. [3]. Cooper et al. [4] proposed a range-adjusted measure (RAM), an extension of the additive model. Aida et al. [5] extended the RAM by reorganizing it as a radial measure, the socalled slack-adjusted radial measure. Tone [6] proposed another type of nonradial model referred to as the slackbased measure (SBM). Similarly, Pastor et al. [7] proposed the enhanced Russell graph measure (ERGM) as a nonradial measure. Sueyoshi and Sekitani [8] and Tone [6] discussed the analytical relationship between the Russel measure, SBM, and ERGM. 
In addition, recent DEA studies have been published in many academic journals. In particular, Farrell-type efficiency measures that are derived from input- or outputoriented DEA formulations are commonly used in many studies. This study employs an output-oriented model for the measurement of efficiency, although the output-oriented radial model is relatively uncommon compared to the inputoriented radial model. The latter is one of the most popular methods in DEA and is used in Ji and Wang [9], Chen et al. [10], Wang et al. [11], Sueyoshi and Wang [12], Wang and Geng [13], and many other articles in recent publications. The basic premise of the input-oriented radial model is that inputs are proportionally contracted given a certain level of outputs, and thus, this model naturally fits with efficiency concepts for firms or other DMUs that make efforts to improve operational efficiency and strengthen cost competitiveness. On the other hand, the basic premise of the output-oriented radial model is that outputs are proportionally augmented given a certain level of inputs, and thus, this model is primarily associated with business motivation for sales promotion and growth. The decision on which type of DEA model is used for a study depends on a researcher's intention regarding the aspects assessed in the efficiency analysis. Since this study examines the efficiency of EPCos under liberalized markets in which the companies compete for growth, we choose to use output-oriented model to assess the growth potential of the companies.

Sueyoshi et al. [14] summarize the trend of DEA studies applied to energy and environment issues. According to the authors' classification, the DEA applications for the electricity industry are categorized into three groups, generation, transmission, and distribution network, and others (e.g., assessment of total operations). Such a classification is due to the unique features of electricity industry. That is, electricity generation has faced competition in many countries in recent years after the market liberalization began in the 1990s, while the transmission and distribution network sector is still under government regulation because it is considered as a natural monopoly sector. The "others" group of research includes assessment of the total operations of electric power utilities, effectiveness of R\&D investment, electricity consumption forecasts, and a literature survey on DEA and other methods applied to the industry.

Studies on transmission and distribution network sector are often associated with regulation because the network sector remains under regulation even after the market liberalization. Indeed, some countries and regions apply benchmarking analysis to network companies' regulation. By contrast, many studies on the generation sector recently have explored various environmental issues (e.g., air pollution and global warming) combined with operational efficiency analysis with the progress of market liberalization and increased public awareness on environmental problems. The number of studies has increased in both categories of "with" and "without" combined analyses. These studies more focus on corporate management than regulation. From this trend of previous studies, it is easily predicted that more researchers will continue to examine not only operational efficiency of
EPCos but also their environmental efficiency by incorporating environmental factors into the efficiency measurement, such as greenhouse gas emissions and waste discharge. All of these emissions are produced from power plants' operations when they generate electricity by using fossil fuels. Further, researchers have been more interested in applying DEA to energy and environment issues in recent years. For example, Souza et al. [15] evaluated efficiency indexes of 60 Brazilian electricity distribution utilities. Wang et al. [16] applied DEA to assess the performance of Indian energy industry. Han et al. [17] measured the energy consumption productivity change of fourteen industry sectors in China. Bi et al. [18] examined regional energy and environmental efficiency of China's transportation sector. Wang and Sueyoshi [19] examined the efficiency of rooftop photovoltaic system installations in California. Although these are only a small part of massive amount of recent literature, these show the new trend of DEA applications to energy and environment issues.

Among the DEA studies applied to energy and environment issues, unique characteristics of this study are summarized as follows. (1) This study is the first contribution to examine operational and environmental efficiencies of Japan's nine major electric power companies using a data set that covers the data before and after the Fukushima nuclear power accident. For example, Sueyoshi and Goto (2015) analyzed Japan's generation fuel mix from a DEA-based comparative study of operational and environmental efficiencies of OECD countries. However, the data set from 1999 to 2011 does not include a period after the Fukushima accident, and the generation data is comprised of national total numbers. Meanwhile, this study uses a company-level data set in electricity industry for the efficiency assessment. (2) This study examines whether operational and environmental efficiencies of EPCos vary during the period, and the efficiencies are different among the companies. Therefore, we can analyze impacts of the market liberalization and Fukushima accident on efficiencies. (3) This study examines whether EPCos develop ecotechnology innovation to improve environmental efficiency. To investigate the ecotechnology innovation, this study uses a new DEA model that was first proposed by Sueyoshi and Goto [20]. Applying the model to the data set provides us with a new insight on managerial efforts for environment of major electric power companies in Japan.

\section{Methodology}

This study applies DEA to measure the operational and environmental efficiencies of EPCos in Japan. DEA is a long-standing methodology to evaluate the performance of organizations in the public and private sectors. Since the seminal paper of Charnes et al. [2] was published, many researchers have proposed various types of DEA models that have different characteristics. For example, DEA models can be classified into eight categories $(2 \times 2 \times 2)$ : (a) radial or nonradial, (b) variable or constant returns to scale (RTS), and (c) input-oriented or output-oriented. Furthermore, DEA models that can assess not only operational but also environmental efficiencies have been proposed by previous studies. 
In evaluating environmental efficiency, outputs are separated into desirable and undesirable categories. Färe et al. [21] introduced weak and strong disposability concepts to discuss environmental efficiency in the context of DEA studies. Sueyoshi and Goto [22] compared weak and strong disposability with natural and managerial disposability. Companies prioritize operational efficiency under natural disposability, while they prioritize environmental efficiency under managerial disposability. Sueyoshi and Goto [20] also discussed that the concept of congestion was separated into undesirable congestion on desirable outputs and desirable congestion on undesirable outputs. The former type of congestion belongs to the conventional definition of congestion. By contrast, the latter type of congestion discusses a new aspect on congestion in DEA environmental assessment. The present study applies the latter congestion concept to a DEA model to explore the occurrence of ecotechnology innovation for reducing undesirable outputs.

The operational and environmental efficiencies of decision-making units (DMUs) are characterized by their production activities that utilize inputs to produce both desirable and undesirable outputs. All inputs, desirable outputs, and undesirable outputs are referred to as "production factors." This study considers $n$ DMUs to be evaluated by DEA. An important feature of DEA assessment is that the achievement of each DMU is relatively compared with those of the remaining others. The performance level is referred to as an "efficiency score" or "efficiency measure."

This study applies an output-oriented radial model (RM) under constant and variable RTS technologies. RMs are widely used for many DEA studies because in general they have an explicit efficiency score that is expressed from $0 \%$ (full inefficiency) to $100 \%$ (full efficiency). This study uses both constant RTS and variable RTS models because we measure scale efficiency of EPCos using efficiency scores from those models. The reason why we use an output-oriented model, not an input-oriented model, is the influence of the market liberalization on the incumbent EPCos examined in this study. Although the electricity industry in Japan is still under the process of the market reform advancing in line with the planned schedule by the government, the business priorities of corporate leaders have been shifting gradually from regulated stability to competition. The share of new entrants, known as power producer and suppliers (PPS), in electricity demand has been increasing gradually since 2000, when the retail market liberalization began from extralarge consumers (the share of PPS in electricity demand varies by region. As of July 2016, shares of PPS supply in electricity demand were $5.9 \%, 14.6 \%, 0.7 \%$, and $1.9 \%$ of the nationwide average for consumers of extrahigh-voltage, high-voltage, low-voltage (nonhousehold), and low-voltage (household) categories, resp.). Given changes in the business environment for the EPCos, this study applies outputoriented DEA models for efficiency assessment under which companies prioritize maximizing desirable outputs rather than minimizing inputs.

Output-oriented RM under managerial disposability and variable RTS, which is originally proposed by Sueyoshi and
Goto [20], has the following mathematical structure of a linear programming problem:

$$
\begin{aligned}
\text { Maximize } & \xi+\varepsilon_{n}\left[\sum_{i=1}^{m} R_{i}^{x} d_{i}^{x}+\sum_{f=1}^{h} R_{f}^{b} d_{f}^{b}\right] \\
\text { s.t. } \quad & \sum_{j=1}^{n} x_{i j} \lambda_{j}-d_{i}^{x}=x_{i k} \quad(i=1, \ldots, m), \\
& \sum_{j=1}^{n} g_{r j} \lambda_{j}-\xi g_{r k}=g_{r k} \quad(r=1, \ldots, s), \\
& \sum_{j=1}^{n} b_{f j} \lambda_{j}+d_{f}^{b}+\xi b_{f k}=b_{f k} \\
& \sum_{j=1}^{n} \lambda_{j}=1, \\
& \lambda_{j} \geq 0 \quad(j=1, \ldots, n), \\
& \xi: U R S, \\
& d_{i}^{x} \geq 0 \quad(i=1, \ldots, m), \\
& d_{f}^{b} \geq 0 \quad(f=1, \ldots, h),
\end{aligned}
$$

where $\xi$ is an inefficiency score of the specific $k$ th DMU and $\varepsilon_{n}$ is a non-Archimedean small number. The specification of $\varepsilon_{n}$ incorporates a subjective decision by a DEA user. This study sets $\varepsilon_{n}$ equal to 0.0001. $x_{i j}$ is an observed value of the $i$ th input $(i=1, \ldots, m)$ on the $j$ th $\operatorname{DMU}(j=1, \ldots, n) ; g_{r j}$ is an observed value of the $r$ th desirable output $(r=1, \ldots, s)$ on the $j$ th $\operatorname{DMU}(j=1, \ldots, n) ; b_{f j}$ is an observed value of the $f$ th undesirable output $(f=1, \ldots, h)$ on the $j$ th $\operatorname{DMU}(j=$ $1, \ldots, n) ; d_{i}^{x}$ is a slack related to the $i$ th input $(i=1, \ldots, m)$; and $d_{f}^{b}$ is a slack related to the $f$ th undesirable output $(f=$ $1, \ldots, h)$. The proposed DEA model needs $\lambda=\left(\lambda_{1}, \ldots, \lambda_{n}\right)^{T}$ to express unknown "intensity" or "structural" variables. In addition, the following three data ranges are used for the objective functions that are related to inputs and undesirable outputs, respectively:

$$
\begin{aligned}
R_{i}^{x} & =(m+h)^{-1}\left(\max \left\{x_{i j} \mid j=1, \ldots, n\right\}\right. \\
& \left.-\min \left\{x_{i j} \mid j=1, \ldots, n\right\}\right)^{-1} \text { for } i=1, \ldots, m, \\
R_{f}^{b} & =(m+h)^{-1}\left(\max \left\{b_{f j} \mid j=1, \ldots, n\right\}\right. \\
& \left.-\min \left\{b_{f j} \mid j=1, \ldots, n\right\}\right)^{-1} \quad \text { for } f=1, \ldots, h .
\end{aligned}
$$

These two data ranges are identified from an observed data set so that they are given to us before the proposed DEA assessment.

It is important to note that the term $\xi+\varepsilon_{n}\left[\sum_{i=1}^{m} R_{i}^{x} d_{i}^{x}+\right.$ $\left.\sum_{f=1}^{h} R_{f}^{b} d_{f}^{b}\right]$ represents a level of inefficiency. The efficiency 
measure is obtained by subtracting the level of inefficiency from unity. Therefore, environmental efficiency (EE) of the $k$ th DMU measured by model (1) is described as follows:

$$
\mathrm{EE}=1-\left(\xi^{*}+\varepsilon_{n}\left[\sum_{i=1}^{m} R_{i}^{x} d_{i}^{x *}+\sum_{f=1}^{h} R_{f}^{b} d_{f}^{b *}\right]\right)
$$

where inefficiency score and all slack variables are determined on the optimality of model (1).

To the best of the authors' knowledge, model (1) has not been widely used in DEA studies so far, since it is a relatively new model. A few exceptions are Sueyoshi and Wang [23] and Sueyoshi and Yuan [24, 25]. Sueyoshi and Yuan [24] applied the model to the measurement of marginal rate of transformation and rate of substitution between production factors for countries in Europe and North America. Sueyoshi and Yuan [25] used the model to examine returns to damage and damages to return on Chinese municipalities. The first study uses $\mathrm{CO}_{2}$ emissions as an undesirable output, just as this study does. The second study uses other environmental pollutants, such as PM10 and $\mathrm{SO}_{2}$, as undesirable outputs. Sueyoshi and Wang [23] applied a similar model to examine investment strategies for 153 observations from S\&P 500 companies over the years 2012-2013, although the constraint on desirable outputs is slightly different from model (1). These studies comparatively assessed the degree of environmental efficiency of DMUs, but their primary concerns are dual variables of production factors. This is because the dual variables are used to measure various economic concepts and identify desirable congestion. The dual variables are derived from model (4) in this study.

To consider the implication further from model (1), we describe the dual formulation of it as follows:

$$
\begin{array}{ll}
\text { Minimize } & -\sum_{i=1}^{m} v_{i} x_{i k}-\sum_{r=1}^{s} u_{r} g_{r k}+\sum_{f=1}^{h} w_{f} b_{f k}+\sigma \\
\text { s.t. } & -\sum_{i=1}^{m} v_{i} x_{i j}-\sum_{r=1}^{s} u_{r} g_{r j}+\sum_{f=1}^{h} w_{f} b_{f j}+\sigma \geq 0 \\
& \\
& \sum_{r=1}^{s} u_{r} g_{r k}+\sum_{f=1}^{h} w_{f} b_{f k}=1 \\
& v_{i} \geq \varepsilon_{s} R_{i}^{x} \quad(i=1, \ldots, n), \\
& u_{r}: U R S \quad(r=1, \ldots, s), \\
& w_{f} \geq \varepsilon_{s} R_{f}^{b} \quad(f=1, \ldots, h), \\
& \sigma: U R S .
\end{array}
$$

A unique feature of model (4) is identified in dual variable $u$, whose sign is unrestricted. That is, these variables can be positive, zero, and negative. The variable $u$ has an important implication for understanding the impact of production on environment protection. A supporting hyperplane for model
(4) is mathematically expressed by $-v x-u g+w b+\sigma=0$, where $v, u$, and $w$ are parameters for indicating slopes and $\sigma$ is an intercept of the supporting hyperplane. The unknown variables, $v$ and $w$, are positive and $u$ and $\sigma$ are unrestricted in their signs. The supporting hyperplane is specified by $b=$ $(v x+u g-\sigma) / w$. Since $w$ is positive, the slope of the supporting hyperplane in $g$ and $b$ dimension is determined by the sign of $u$. This study follows the definition of Sueyoshi and Goto [20] regarding congestion. That is, (a) if $u$ is negative, it indicates an occurrence of strong desirable congestion (DC),

(b) if $u$ is zero, it indicates an occurrence of weak DC, and (c) if $u$ is positive, it indicates an occurrence of no DC. Here, strong DC implies that an increase in desirable output and a decrease in undesirable output coexist, indicating the occurrence of ecotechnology innovation or improvement of managerial efficiency for environmental protection.

Next, we examine the operational performance of each EPCo without incorporating the influence of $\mathrm{CO}_{2}$ emissions as an undesirable output by solving model (5) as follows:

$$
\begin{array}{ll}
\text { Maximize } & \xi+\varepsilon_{n}\left[\sum_{i=1}^{m} R_{i}^{x} d_{i}^{x}+\sum_{r=1}^{s} R_{r}^{g} d_{r}^{g}\right] \\
\text { s.t. } & \sum_{j=1}^{n} x_{i j} \lambda_{j}+d_{i}^{x}=x_{i k} \quad(i=1, \ldots, m), \\
& \sum_{j=1}^{n} g_{r j} \lambda_{j}-d_{r}^{g}-\xi_{g_{r k}}=g_{r k} \\
& \sum_{j=1}^{n} \lambda_{j}=1, \\
& \lambda_{j} \geq 0 \quad(j=1, \ldots, n), \\
& \xi: U R S, \\
& d_{i}^{x} \geq 0 \quad(i=1, \ldots, m), \\
& d_{r}^{g} \geq 0 \quad(r=1, \ldots, s) .
\end{array}
$$

Here, $R_{r}^{g}=(m+s)^{-1}\left(\max \left\{g_{r j} \mid j=1, \ldots, n\right\}-\min \left\{g_{r j} \mid\right.\right.$ $j=1, \ldots, n\})^{-1}$ for $r=1, \ldots, s$. As shown above, model (5) includes a constraint equation for a desirable output, not for an undesirable output, as observed in model (1). In addition, as model (5) is primarily interested in operational efficiency, natural disposability is employed in the formulation, so the sign of $d_{i}^{x}$ is opposite to that in model (1). Furthermore, the slack variable for desirable outputs, $d_{r}^{g}(r=1, \ldots, s)$, is added to the constraint equation for desirable outputs. Then, the efficiency score of the $k$ th DMU is measured by subtracting inefficiency from unity. In concrete terms, (6) defines the operational efficiency (OE) of a firm, which does not incorporate undesirable outputs for the efficiency assessment.

$$
\mathrm{OE}=1-\left(\xi^{*}+\varepsilon_{n}\left[\sum_{i=1}^{m} R_{i}^{x} d_{i}^{x *}+\sum_{r=1}^{s} R_{r}^{g} d_{r}^{g *}\right]\right),
$$


where all slack variables and the inefficiency score are determined by the optimality of model (5). Note that models (1) and (5) are formulated under variable RTS (VRTS) technology. If a constraint $\sum_{j=1}^{n} \lambda_{j}=1$ is deleted from the models, constant RTS (CRTS) technology is assumed.

\section{An Application to the Japanese Electric Power Industry}

4.1. Japanese Electric Power Industry and Market Reform. A global trend in electricity market reform started in the early 1990s. For example, the Electricity Act of 1989 in the UK implemented vertical unbundling and privatization of the electricity supply industry. In line with the global trend, Japan's Electricity Business Act (EBA) was amended in 1995 for the first time since its enactment in 1964. Under the amendment, partial competition was introduced into the electricity generation market as competitive bidding for new generation capacities. More amendments followed in 1999 and 2003. After the 1999 amendment of the EBA was enacted, retail competition began in 2000 for those consumers with relatively high demand, defined as $20,000 \mathrm{~V}$ and $2,000 \mathrm{~kW}$ or more. The third amendment, in 2003, twice expanded the eligibility of consumers to include those with demand size of $500 \mathrm{~kW}$ or more in April 2004 and those with $50 \mathrm{~kW}$ or more in April 2005. The other important changes in the third revision of the EBA were (1) the establishment of a neutral organization for fair and transparent network sector operation and accounting unbundling of the network sector from other sectors and (2) the establishment of a wholesale power market. After the third amendment in 2003, full retail competition that extends eligibility to household consumers was not introduced, but instead was left for future discussions, because the government considered consumer benefits were unclear. Thus, after the implementation of the three EBA amendments in 1995, 1999, and 2003, no major progress was made in electricity market liberalization in Japan at the pace observed in the US and European countries.

The reason for Japan's slowdown in liberalization is partly explained by the 2000-2001 California electricity crisis. Policymakers and corporate leaders in the electricity industry understood there were risks associated with the advancement of market liberalization and competition. Under these circumstances, the electricity industry solidly and successfully opposed further promotion of market liberalization and took cautious steps toward structural changes of the industry. However, even in light of the California crisis, the US and countries in Europe advanced market liberalization, and, therefore, electricity market reform in Japan during this period fell behind that of other countries.

The business environment surrounding the Japanese electricity industry has changed drastically since the Fukushima Daiichi nuclear power plant accident (see Goto and Sueyoshi [26] for details about the electricity market liberalization process after the Fukushima Daiichi nuclear power plant accident on March 11, 2011). Immediately after the accident, under the administration of the Democratic Party of Japan (DPJ), the Japanese government began intensive discussions on the future of energy policy by establishing numerous committees to address energy issues. The National Policy Unit (NPU) of the Cabinet Secretariat, established in September 2009 under the DPJ's administration, conducted top-down policy review led by the Prime Minister and Cabinet. It organized the Energy and Environment Council, which summarized and published the Innovative Strategy for Energy and the Environment in September 2012. That report laid out the basic policy direction of Japan's future energy plans. The NPU was abolished when the Liberal Democratic Party became the ruling party after the 2012 national election. However, the basic direction of electricity market reform was embraced by the new government and was considered an important economic growth strategy by creating new energy markets.

After continuous discussions, the Cabinet approved a reform strategy for the electricity system on April 2, 2013. The strategy comprises three policy tasks: first, to promote crossregional operation of the transmission grid system; second, to realize fully liberalized markets in the retail and generation sectors; and third, to make progress in the unbundling of the transmission-distribution network in a framework of legal separation. The first and second steps were already implemented in 2015 and 2016, respectively. The third reform or network unbundling is meant to be concluded by 2020 .

4.2. Hypotheses. Based on progress in the electricity market reform discussed above, this study proposes the following three hypotheses on the development of operational and environmental efficiencies of the Japanese electric power industry:

(H1) Market liberalization and the Fukushima nuclear power plant accident have not influenced the operational and environmental performance of the Japanese electric power industry.

(H2) Japanese EPCos showed the same results in their operational and environmental performances even after market liberalization and the Fukushima nuclear power plant accident.

(H3) Japanese EPCos have made efforts to use ecotechnology innovation for environmental protection against global warming and climate change.

(H1) is proposed due to our expectation that market liberalization and the Fukushima accident have not yet had a major impact on the performance of the incumbent EPCos. The reason is that full retail market liberalization began only in April 2016 and the previous liberalization of the retail market was not effective enough to increase the switching of industry and commercial consumers from incumbent suppliers. In addition, competition in the wholesale power market has not been active since it started operation in 1995 because of low trading volumes.

(H2) is proposed because the business freedom after market liberalization has not yet produced different business strategies among EPCos under strong governmental regulation. In addition to the common application of market liberalization to all incumbent EPCos, the compensation 
problem of the nuclear power plant accident influenced not only Tokyo EPCo but also the other incumbent EPCos, with the exception of Okinawa EPCo. Okinawa EPCo. is excluded from this study because it is very small in operation size and does not have any nuclear power plants. In other words, the compensation cost burden has been allocated to the other EPCos through the industry-wide compensation scheme, so it is not expected to see drastic performance variations among EPCos. To examine (H1) and (H2) statistically, this study uses the Kruskal-Wallis rank sum test.

(H3) is proposed owing to expectations of the influence of global consciousness for environmental protection, particularly following the Kyoto Protocol. Japanese EPCos' operations are expected to have been influenced by the trend so that they reduced $\mathrm{CO}_{2}$ emissions from power generation even after the occurrence of the Fukushima nuclear accident and the Japanese government's decision to leave the second period commitment of the Kyoto Protocol.

4.3. Data. Table 1 presents the descriptive statistics of the data. We use three inputs, three desirable outputs, and one undesirable output. The three inputs consist of total assets, total debts, and operating expenses. All variables are used to operate EPCos' business. Under the assumption of natural disposability, EPCos make efforts to reduce inputs as much as possible to attain a certain level of desirable outputs. In particular, regarding total assets, it is well known that EPCos might overinvest in their facilities because their revenue increases in parallel with the amount of capital assets under the "fair rate of return" criterion. Under the criterion, a firm subtracts its operating expense from gross revenue, and the remaining net revenue should be sufficient to compensate the firm for its investment in plant and equipment. If the rate of return, computed as the ratio of net revenue to the value of plant and equipment (the rate base), is judged as excessive, political pressure is brought to bear on the EPCo to reduce electricity prices. If the rate is considered too low, the firm is permitted to increase prices. Because of the price-setting mechanism, or rate of return regulation, the EPCos tend to be motivated for overinvestment in plant and equipment, which leads to an augmented rate base to produce higher revenue. This type of overinvestment under regulation is often referred to as the Averch-Johnson effect. Given this concern, the present study is interested in the efficient use of assets of Japanese EPCos. In contrast, under the assumption of managerial disposability, EPCos can increase inputs as long as the increase produces more desirable outputs and less undesirable outputs.

The three desirable outputs are comprised of total revenue, total enterprise value, and total electricity sold to consumers. All these variables are associated with values produced from EPCos' operations and the companies are assumed to increase these amounts as much as possible from a certain level of inputs for better performance. One undesirable output is the amount of $\mathrm{CO}_{2}$ emissions, mainly from power generation. It is expected that EPCos intend to reduce the amount of $\mathrm{CO}_{2}$ emissions as much as possible under the condition that they produce a certain level of
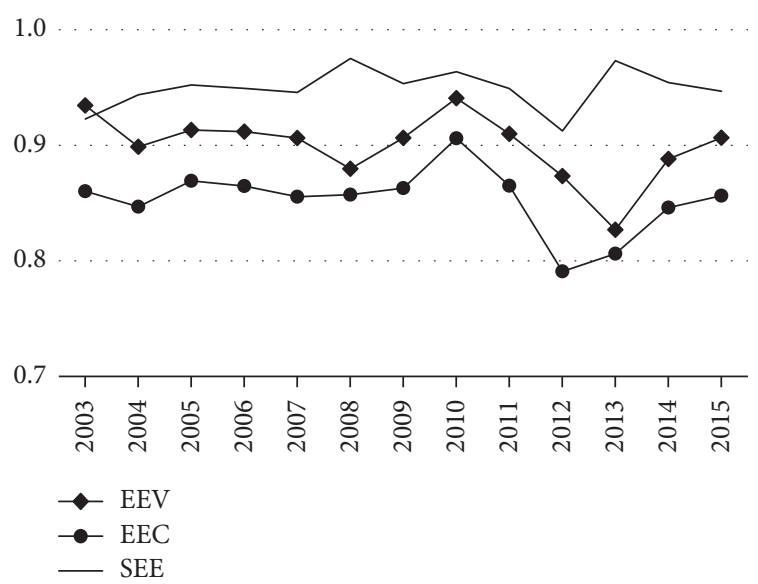

FIgure 1: Trend of EEV, EEC, and SEE.

desirable outputs by using a certain level of inputs. Table 1 clearly indicates that Tokyo EPCo is the largest among them; for example, its total revenue is more than double, compared to that of the Kansai and Chubu, the second and third largest companies, respectively. The statistics show the strong position of Tokyo EPCo in the electricity industry in Japan.

4.4. Empirical Results. Table 2 summarizes the results of environmental efficiency measured by model (1) for the nine EPCos from 2003 to 2015. The upper panel indicates environmental efficiency under VRTS technology (EEV), the middle panel indicates that under CRTS technology (EEC), and the lower panel describes scale efficiency for environmental efficiency (SEE), which is calculated by dividing EEC by EEV. In addition, Figure 1 depicts the development of EEV, EEC, and SEE on the company average from 2003 to 2015.

Tokyo EPCo has the highest EEV with 0.998 on average, followed by Kansai (0.966) and Chubu and Shikoku ( 0.953 for both companies). These companies are relatively big EPCos in Japan with the exception of Shikoku. In particular, Tokyo EPCo, the largest among them, as shown in Table 1, kept its high level of efficiency from 2003 to 2014, although it fell to 0.978 in 2015. This result for Tokyo EPCo is surprising particularly for the last several years because Tokyo EPCo's operations were significantly damaged by the Fukushima Daiichi nuclear power accident at the end of the 2010 fiscal year (March 11, 2011) (2010 fiscal year begins on 1st of April 2010 and ends on 31st of March 2011), leading us to expect that the company significantly decreased efficiency levels from 2010 due to the deteriorating total enterprise value after the accident. Indeed, six among nine companies decreased their total enterprise values in 2015 compared to those in 2003, decreasing by $8.8 \%$ (Tohoku), 38.2\% (Tokyo), 29.7\% (Chubu), 26.1\% (Hokuriku), 12\% (Kansai), and 12\% (Shikoku). However, the results are different from the expectation. One reason is that the damage to the corporate value of Tokyo EPCo was extended to the other EPCos because all the other eight companies own nuclear power plants and the market had concerns about the potential risk of nuclear power generation itself for those companies. Hence, the decreased 


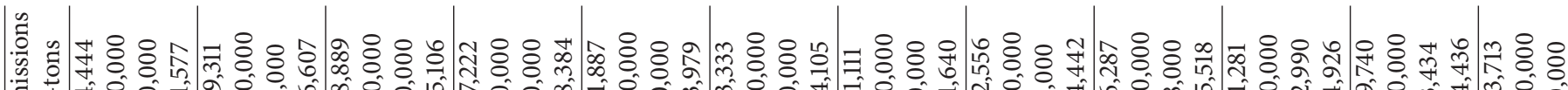

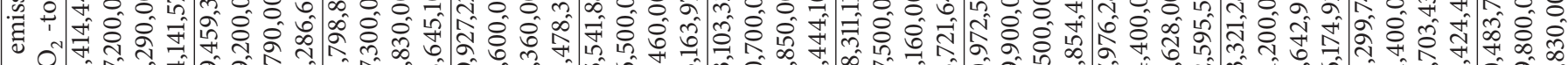

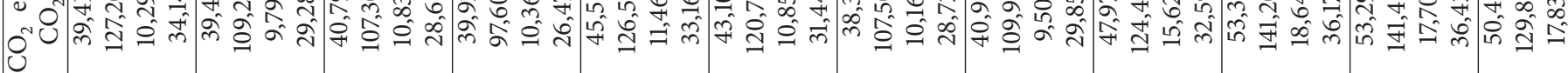

\section{$\cong$}

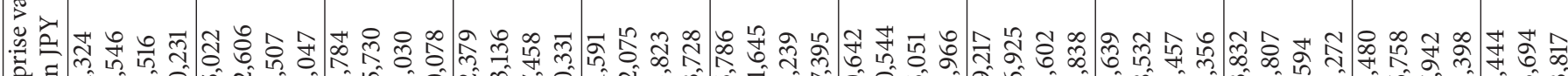

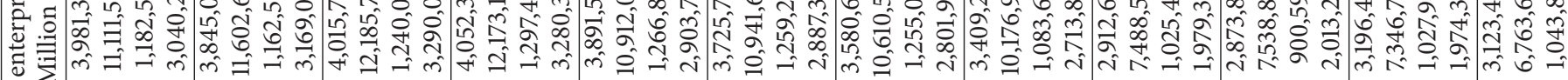
胥

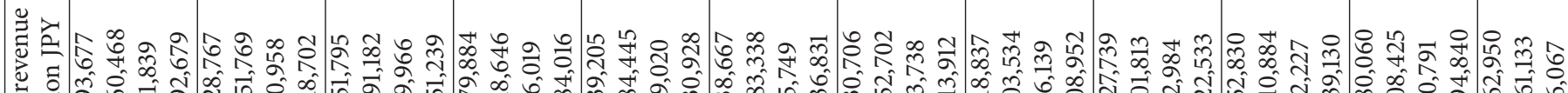

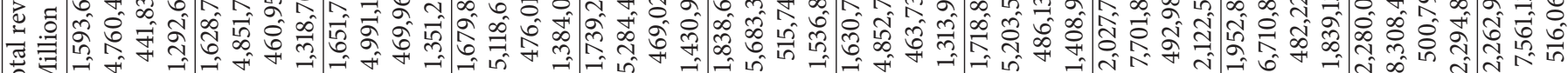

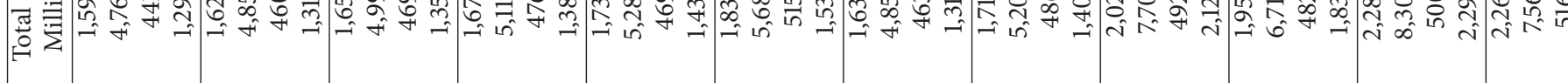

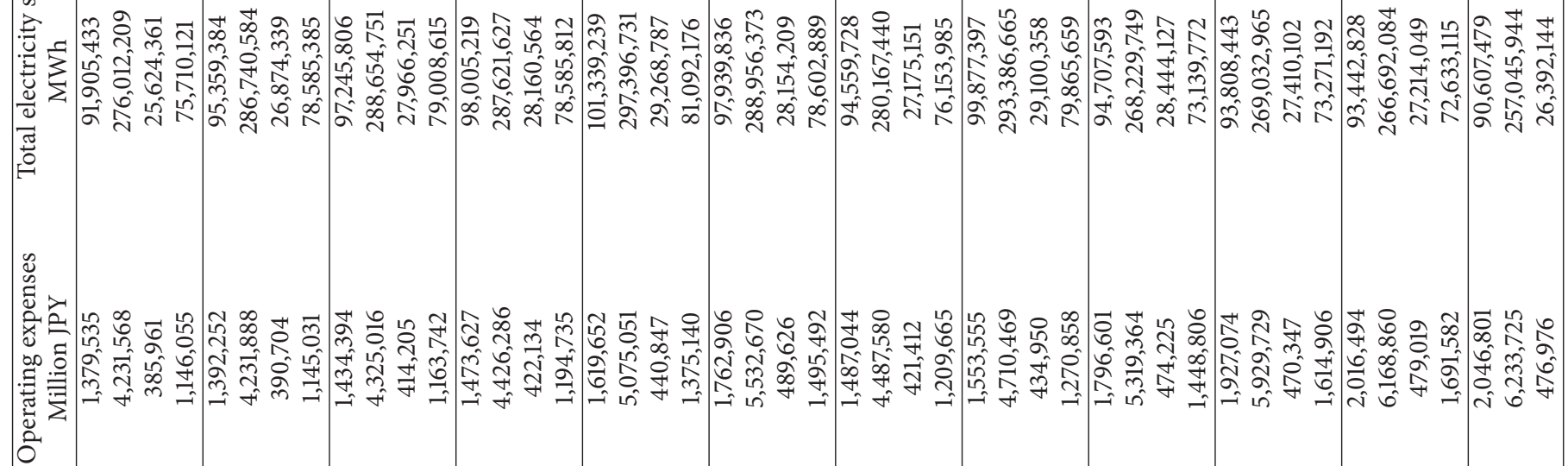

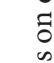

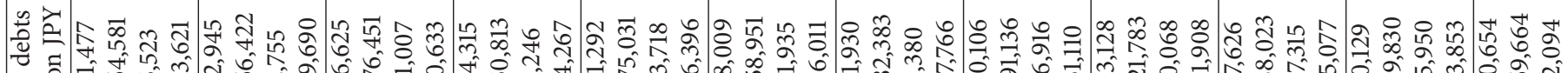

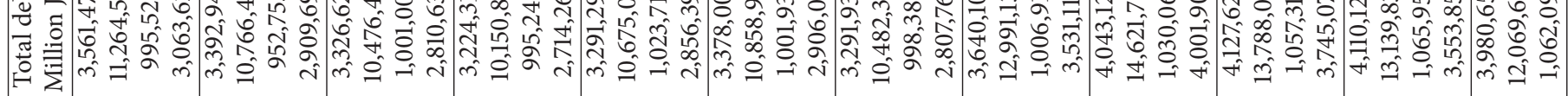

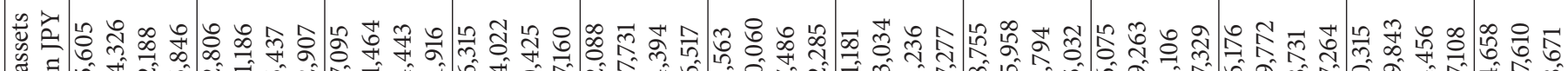

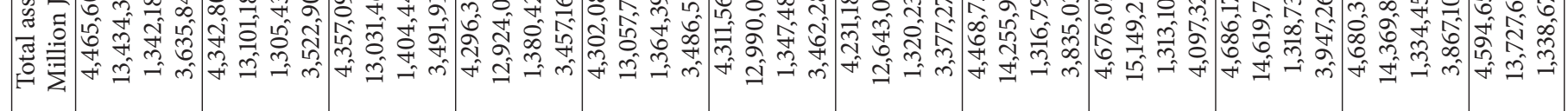

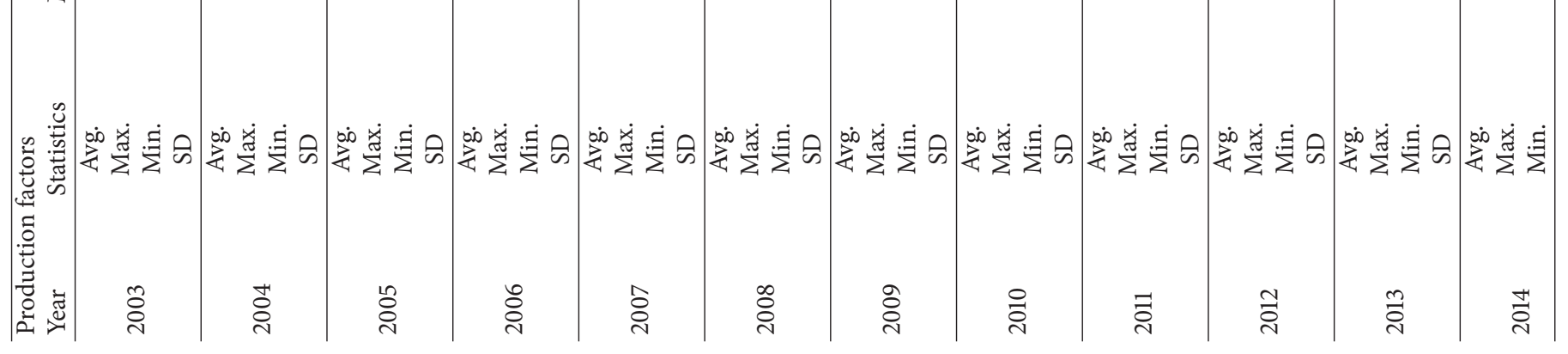




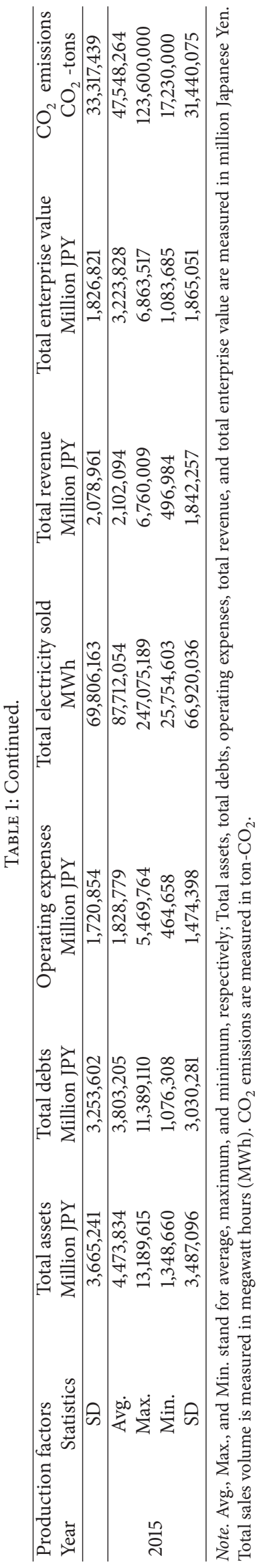


TABLE 2: Results of environmental efficiency for nine electric power companies.

\begin{tabular}{|c|c|c|c|c|c|c|c|c|c|}
\hline & Hokkaido & Tohoku & Tokyo & Chubu & Hokuriku & Kansai & Chugoku & Shikoku & Kyushu \\
\hline \multicolumn{10}{|c|}{ EEV: model (1) environmental efficiency (VRTS) } \\
\hline 2003 & 0.768 & 1.000 & 1.000 & 1.000 & 1.000 & 1.000 & 0.642 & 1.000 & 1.000 \\
\hline 2004 & 0.783 & 0.819 & 1.000 & 0.934 & 1.000 & 0.908 & 0.644 & 1.000 & 1.000 \\
\hline 2005 & 0.838 & 0.774 & 1.000 & 1.000 & 1.000 & 1.000 & 0.649 & 0.959 & 1.000 \\
\hline 2006 & 0.826 & 0.830 & 1.000 & 1.000 & 0.908 & 1.000 & 0.645 & 0.998 & 1.000 \\
\hline 2007 & 0.802 & 0.788 & 1.000 & 1.000 & 1.000 & 0.937 & 0.641 & 0.988 & 1.000 \\
\hline 2008 & 0.697 & 1.000 & 1.000 & 0.837 & 0.850 & 1.000 & 0.624 & 1.000 & 0.909 \\
\hline 2009 & 0.910 & 0.815 & 1.000 & 0.854 & 1.000 & 1.000 & 0.628 & 0.952 & 1.000 \\
\hline 2010 & 1.000 & 0.877 & 1.000 & 1.000 & 1.000 & 1.000 & 0.590 & 1.000 & 1.000 \\
\hline 2011 & 1.000 & 1.000 & 1.000 & 1.000 & 0.792 & 1.000 & 0.646 & 0.751 & 1.000 \\
\hline 2012 & 0.749 & 0.749 & 1.000 & 1.000 & 1.000 & 0.910 & 0.629 & 1.000 & 0.823 \\
\hline 2013 & 1.000 & 0.889 & 1.000 & 0.939 & 0.761 & 0.798 & 0.608 & 0.737 & 0.709 \\
\hline 2014 & 0.837 & 1.000 & 1.000 & 0.949 & 0.712 & 1.000 & 0.645 & 1.000 & 0.851 \\
\hline 2015 & 1.000 & 1.000 & 0.978 & 0.873 & 0.641 & 1.000 & 0.667 & 1.000 & 1.000 \\
\hline Average & 0.862 & 0.888 & 0.998 & 0.953 & 0.897 & 0.966 & 0.635 & 0.953 & 0.946 \\
\hline \multicolumn{10}{|c|}{ EEC: model (1) environmental efficiency (CRTS) } \\
\hline 2003 & 0.713 & 0.874 & 0.760 & 0.856 & 1.000 & 1.000 & 0.621 & 1.000 & 0.919 \\
\hline 2004 & 0.705 & 0.811 & 0.844 & 0.879 & 0.924 & 0.892 & 0.623 & 0.944 & 1.000 \\
\hline 2005 & 0.730 & 0.767 & 0.843 & 1.000 & 1.000 & 0.950 & 0.633 & 0.900 & 1.000 \\
\hline 2006 & 0.719 & 0.828 & 0.895 & 0.920 & 0.873 & 0.969 & 0.633 & 0.946 & 1.000 \\
\hline 2007 & 0.713 & 0.782 & 0.842 & 0.835 & 1.000 & 0.907 & 0.633 & 0.987 & 1.000 \\
\hline 2008 & 0.667 & 0.944 & 0.916 & 0.837 & 0.838 & 1.000 & 0.615 & 1.000 & 0.897 \\
\hline 2009 & 0.789 & 0.807 & 0.874 & 0.853 & 0.929 & 1.000 & 0.607 & 0.908 & 1.000 \\
\hline 2010 & 0.904 & 0.869 & 1.000 & 1.000 & 0.861 & 1.000 & 0.571 & 0.949 & 1.000 \\
\hline 2011 & 0.812 & 1.000 & 1.000 & 0.970 & 0.652 & 1.000 & 0.637 & 0.715 & 1.000 \\
\hline 2012 & 0.646 & 0.743 & 1.000 & 1.000 & 0.728 & 0.910 & 0.620 & 0.661 & 0.810 \\
\hline 2013 & 1.000 & 0.853 & 1.000 & 0.937 & 0.660 & 0.797 & 0.598 & 0.703 & 0.708 \\
\hline 2014 & 0.837 & 1.000 & 1.000 & 0.934 & 0.650 & 1.000 & 0.644 & 0.731 & 0.818 \\
\hline 2015 & 1.000 & 0.982 & 0.969 & 0.870 & 0.608 & 0.891 & 0.651 & 0.798 & 0.938 \\
\hline Average & 0.787 & 0.866 & 0.919 & 0.915 & 0.825 & 0.947 & 0.622 & 0.865 & 0.930 \\
\hline \multicolumn{10}{|c|}{ SEE: scale efficiency } \\
\hline 2003 & 0.928 & 0.874 & 0.760 & 0.856 & 1.000 & 1.000 & 0.967 & 1.000 & 0.919 \\
\hline 2004 & 0.900 & 0.990 & 0.844 & 0.941 & 0.924 & 0.983 & 0.968 & 0.944 & 1.000 \\
\hline 2005 & 0.871 & 0.991 & 0.843 & 1.000 & 1.000 & 0.950 & 0.976 & 0.939 & 1.000 \\
\hline 2006 & 0.870 & 0.999 & 0.895 & 0.920 & 0.961 & 0.969 & 0.983 & 0.948 & 1.000 \\
\hline 2007 & 0.888 & 0.992 & 0.842 & 0.835 & 1.000 & 0.968 & 0.987 & 0.999 & 1.000 \\
\hline 2008 & 0.957 & 0.944 & 0.916 & 0.999 & 0.986 & 1.000 & 0.986 & 1.000 & 0.987 \\
\hline 2009 & 0.868 & 0.991 & 0.874 & 0.998 & 0.929 & 1.000 & 0.967 & 0.954 & 1.000 \\
\hline 2010 & 0.904 & 0.991 & 1.000 & 1.000 & 0.861 & 1.000 & 0.968 & 0.949 & 1.000 \\
\hline 2011 & 0.812 & 1.000 & 1.000 & 0.970 & 0.824 & 1.000 & 0.985 & 0.951 & 1.000 \\
\hline 2012 & 0.863 & 0.991 & 1.000 & 1.000 & 0.728 & 1.000 & 0.985 & 0.661 & 0.985 \\
\hline 2013 & 1.000 & 0.959 & 1.000 & 0.997 & 0.867 & 0.998 & 0.985 & 0.953 & 0.999 \\
\hline 2014 & 1.000 & 1.000 & 1.000 & 0.985 & 0.913 & 1.000 & 0.999 & 0.731 & 0.961 \\
\hline 2015 & 1.000 & 0.982 & 0.991 & 0.997 & 0.949 & 0.891 & 0.976 & 0.798 & 0.938 \\
\hline Average & 0.913 & 0.976 & 0.920 & 0.960 & 0.919 & 0.981 & 0.980 & 0.908 & 0.984 \\
\hline
\end{tabular}

corporate enterprise value did not clearly influence their relative performance. This similarity among the nine incumbent EPCos under uniform government regulation has been conventionally observed in Japan. The worst performance with regard to EEV was by Chugoku EPCo, with an average 0.635, followed by Hokkaido (0.862), Tohoku (0.888), and Hokuriku (0.897). The reason for the lower environmental efficiency of Chugoku and Tohoku is clear because they have both had continuously low shares of nuclear power generation, and thus, their carbon intensity is relatively high among the nine EPCos.

Shifting to the results for EEC, shown in the middle panel of Table 2, we find that overall efficiency levels are lower than those in the upper panel showing EEV. This is because of the mathematical structure of DEA models under VRTS and CRTS technologies. However, it is interesting to observe that several companies show relatively large decreases in EEC compared to EEV, including Tokyo from 0.998 to 0.919 , 
TABLE 3: Results of operational efficiency for nine electric power companies.

\begin{tabular}{|c|c|c|c|c|c|c|c|c|c|}
\hline & Hokkaido & Tohoku & Tokyo & Chubu & Hokuriku & Kansai & Chugoku & Shikoku & Kyushu \\
\hline \multicolumn{10}{|c|}{ OEV: model (5) operational efficiency (VRTS) } \\
\hline 2003 & 1.000 & 0.952 & 0.971 & 1.000 & 1.000 & 0.979 & 0.950 & 1.000 & 0.968 \\
\hline 2004 & 1.000 & 0.911 & 1.000 & 1.000 & 1.000 & 0.994 & 0.996 & 1.000 & 0.984 \\
\hline 2005 & 0.989 & 0.936 & 1.000 & 1.000 & 1.000 & 0.992 & 0.990 & 0.952 & 0.969 \\
\hline 2006 & 1.000 & 0.950 & 1.000 & 1.000 & 0.994 & 0.986 & 1.000 & 0.976 & 0.973 \\
\hline 2007 & 1.000 & 0.949 & 1.000 & 1.000 & 0.979 & 0.980 & 1.000 & 1.000 & 0.958 \\
\hline 2008 & 0.873 & 0.936 & 1.000 & 0.997 & 0.980 & 0.935 & 0.961 & 1.000 & 0.922 \\
\hline 2009 & 0.899 & 0.912 & 0.986 & 0.994 & 1.000 & 0.947 & 0.950 & 1.000 & 0.922 \\
\hline 2010 & 0.902 & 0.922 & 1.000 & 1.000 & 1.000 & 0.979 & 0.954 & 1.000 & 0.936 \\
\hline 2011 & 0.911 & 0.751 & 1.000 & 0.932 & 0.956 & 0.868 & 0.934 & 1.000 & 0.764 \\
\hline 2012 & 0.819 & 0.812 & 0.959 & 0.913 & 0.920 & 0.830 & 0.894 & 0.939 & 0.716 \\
\hline 2013 & 0.755 & 0.935 & 1.000 & 0.956 & 0.885 & 0.898 & 0.924 & 1.000 & 0.867 \\
\hline 2014 & 0.834 & 1.000 & 1.000 & 1.000 & 0.896 & 0.919 & 0.920 & 0.994 & 0.847 \\
\hline 2015 & 0.876 & 0.979 & 0.970 & 1.000 & 0.855 & 0.961 & 0.912 & 0.978 & 0.891 \\
\hline Average & 0.912 & 0.919 & 0.991 & 0.984 & 0.959 & 0.944 & 0.953 & 0.988 & 0.901 \\
\hline \multicolumn{10}{|c|}{ OEC: model (5) operational efficiency (CRTS) } \\
\hline 2003 & 0.990 & 0.951 & 0.903 & 1.000 & 1.000 & 0.965 & 0.937 & 0.956 & 0.967 \\
\hline 2004 & 0.980 & 0.907 & 0.938 & 1.000 & 1.000 & 0.987 & 0.983 & 0.960 & 0.982 \\
\hline 2005 & 0.948 & 0.935 & 0.959 & 1.000 & 1.000 & 0.982 & 0.975 & 0.931 & 0.964 \\
\hline 2006 & 0.979 & 0.948 & 0.969 & 1.000 & 0.971 & 0.976 & 0.979 & 0.955 & 0.963 \\
\hline 2007 & 0.925 & 0.948 & 0.903 & 1.000 & 0.936 & 0.969 & 0.989 & 1.000 & 0.947 \\
\hline 2008 & 0.806 & 0.935 & 0.916 & 0.997 & 0.980 & 0.913 & 0.948 & 1.000 & 0.918 \\
\hline 2009 & 0.857 & 0.905 & 0.909 & 0.993 & 0.940 & 0.938 & 0.937 & 0.957 & 0.917 \\
\hline 2010 & 0.871 & 0.915 & 0.885 & 1.000 & 0.923 & 0.965 & 0.942 & 0.948 & 0.928 \\
\hline 2011 & 0.832 & 0.745 & 1.000 & 0.927 & 0.864 & 0.822 & 0.921 & 0.897 & 0.761 \\
\hline 2012 & 0.694 & 0.805 & 0.866 & 0.902 & 0.838 & 0.781 & 0.878 & 0.785 & 0.706 \\
\hline 2013 & 0.752 & 0.934 & 1.000 & 0.949 & 0.834 & 0.866 & 0.924 & 0.936 & 0.864 \\
\hline 2014 & 0.832 & 1.000 & 0.957 & 1.000 & 0.849 & 0.880 & 0.917 & 0.912 & 0.844 \\
\hline 2015 & 0.873 & 0.978 & 0.942 & 1.000 & 0.826 & 0.949 & 0.911 & 0.920 & 0.890 \\
\hline Average & 0.872 & 0.916 & 0.934 & 0.982 & 0.920 & 0.923 & 0.942 & 0.935 & 0.896 \\
\hline \multicolumn{10}{|c|}{ SOE: scale efficiency } \\
\hline 2003 & 0.990 & 0.999 & 0.930 & 1.000 & 1.000 & 0.986 & 0.987 & 0.956 & 0.999 \\
\hline 2004 & 0.980 & 0.996 & 0.938 & 1.000 & 1.000 & 0.994 & 0.987 & 0.960 & 0.997 \\
\hline 2005 & 0.958 & 0.999 & 0.959 & 1.000 & 1.000 & 0.989 & 0.984 & 0.978 & 0.995 \\
\hline 2006 & 0.979 & 0.998 & 0.969 & 1.000 & 0.977 & 0.989 & 0.979 & 0.978 & 0.990 \\
\hline 2007 & 0.925 & 0.999 & 0.903 & 1.000 & 0.956 & 0.989 & 0.989 & 1.000 & 0.989 \\
\hline 2008 & 0.924 & 0.998 & 0.916 & 1.000 & 1.000 & 0.976 & 0.986 & 1.000 & 0.995 \\
\hline 2009 & 0.953 & 0.993 & 0.922 & 0.999 & 0.940 & 0.990 & 0.987 & 0.957 & 0.995 \\
\hline 2010 & 0.965 & 0.993 & 0.885 & 1.000 & 0.923 & 0.986 & 0.988 & 0.948 & 0.991 \\
\hline 2011 & 0.913 & 0.993 & 1.000 & 0.995 & 0.904 & 0.947 & 0.986 & 0.897 & 0.996 \\
\hline 2012 & 0.847 & 0.992 & 0.903 & 0.988 & 0.911 & 0.941 & 0.982 & 0.836 & 0.985 \\
\hline 2013 & 0.997 & 0.999 & 1.000 & 0.993 & 0.943 & 0.964 & 1.000 & 0.936 & 0.997 \\
\hline 2014 & 0.998 & 1.000 & 0.957 & 1.000 & 0.947 & 0.958 & 0.997 & 0.918 & 0.997 \\
\hline 2015 & 0.996 & 0.999 & 0.972 & 1.000 & 0.967 & 0.987 & 0.999 & 0.941 & 1.000 \\
\hline Average & 0.956 & 0.997 & 0.943 & 0.998 & 0.960 & 0.977 & 0.988 & 0.947 & 0.994 \\
\hline
\end{tabular}

Hokkaido from 0.862 to 0.787 , Hokuriku from 0.897 to 0.825 , and Shikoku from 0.953 to 0.865 , on year averages. Those companies are characterized by inefficient scale management, which leads to lower SEE, as presented in the lower panel of Table 2.

Another unique feature is found in Hokkaido, Tokyo, Hokuriku, and Shikoku. Hokkaido and Tokyo largely increased their EEC from 0.713 and 0.760 in 2003 to 1 and 0.969 in 2015, respectively. These EPCos drastically improved their efficiency levels over the period. Meanwhile, Hokuriku and Shikoku decreased their levels of EEC from 1 for both in 2003 to 0.608 (Hokuriku) and 0.798 (Shikoku) in 2015. These two companies are among the smaller companies of Japan's nine EPCos, and thus, their operations were negatively influenced by scale economies. Indeed, these two companies and Hokkaido, another smaller company, have lower SEE levels among EPCos.

Table 3 shows the operational efficiency under VRTS technology (OEV) in the upper panel, operational efficiency under CRTS technology (OEC) in the middle panel, and scale 


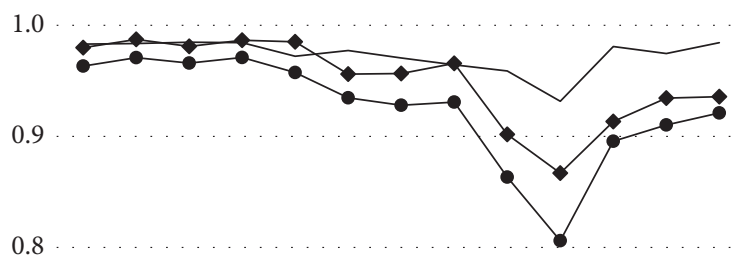

0.8

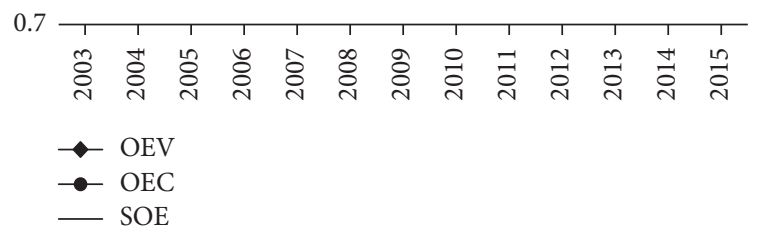

Figure 2: Trend of OEV, OEC, and SOE.

efficiency for operational efficiency (SOE) in the lower panel. In addition, Figure 2 depicts the development of OEV, OEC, and SOE on the company average from 2003 to 2015.

The results of operational efficiency indicate that Tokyo EPCo is the most efficient among the nine EPCos with OEV of 0.991, followed by Shikoku (0.988) and Chubu (0.984). The results are similar to those for EEV except that Kansai EPCo decreased its efficiency level. Meanwhile, OEC shows different results from those for OEV. The most efficient EPCo is Chubu with 0.982, followed by Chugoku with 0.942 and Shikoku with 0.935 . It is noteworthy that Tokyo EPCo does not belong to the top three for OEC, although it is ranked fourth and increased its efficiency level from 0.903 in 2003 to 0.942 in 2015. In other words, on a relative basis, Tokyo EPCo does not perform well in operational scale management and its SOE is the lowest among the nine EPCos with 0.943 .

Table 4 shows the results of the Kruskal-Wallis rank sum test for (H1) and (H2). The results of the test on (H1) for efficiency change over time indicate there are no statistically significant changes in EEV, EEC, SEE, and SOE over the period 2003-2015, while OEV and OEC present significant changes during this period. Next, we test (H2), or efficiency differences among EPCos. The result indicates statistically significant differences in all efficiency scores: EEV, EEC, SEE, OEV, OEC, and SOE.

From the results presented in Table 4 and Figures 1 and 2, we conclude that environmental efficiencies or EEV and EEC of EPCos were statistically invariant over the period 2003-2015, while operational efficiencies or OEV and OEC decreased in the same period. In particular, environmental efficiencies and operational efficiencies both decreased from 2010 to 2013 from the influence of the Fukushima Daiichi nuclear power plant accident, and they mostly recovered toward 2015. However, the extent of recovery was not sufficient on the operational efficiencies. This trend implies that the Fukushima accident significantly influenced EPCos' operational efficiency, but not their environmental efficiency. In addition, efficiency levels for all measures, EEV, EEC, SEE, OEV, OEC, and SOE, are different among EPCos over the study period. This might be due to the progress of the electricity market reform. However, on the other hand, the stable differences among EPCos might be arising from fixed positions of EPCos under the gradual progress of electricity market reform.

Next, Table 5 indicates $u_{r}(r=1, \ldots, s)$ for model (4). As described in Section 3 for model (4), a negative $u_{r}$ signals the occurrence of DC or ecotechnology innovation regarding the desirable outputs. That is, an increase in desirable output and a decrease in undesirable output coexist and improvement of managerial efficiency for environmental protection occurs. Such negative $u_{r}$ is observed at least in a few years in all companies for all desirable outputs-total revenue, total enterprise value, and total electricity sold-with the exception of Shikoku on total revenue. Negative $u_{r}$ appears particularly often with respect to total revenue and total enterprise value for most EPCos, although Tohoku and Shikoku do not frequently show such negative values of $u_{r}$ for total revenue and Tokyo and Shikoku do not for total enterprise value. Meanwhile, such negative values do not appear so often for total electricity sold for most of EPCos with the exception of Shikoku. At the bottom of Table 5, we present the percentage of negative values of $u_{r}$ for each company for three desirable outputs in total. The percentage ranges from 38\% for Tokyo and Shikoku to 56\% for Kyushu. From the results, this study suggests that Japanese EPCos have been undertaking efforts to promote environmental protection using ecotechnology innovation to lower $\mathrm{CO}_{2}$ emissions while keeping or increasing production of desirable outputs in approximately $50 \%$ operation data points. This result partially proves $(\mathrm{H} 3)$ on ecotechnology innovation.

\section{Conclusion}

This study examined operational and environmental efficiencies of nine incumbent EPCos in Japan using a data set from 2003 to 2015. This study applied output-oriented radial DEA model to the measurement of efficiencies. Three inputs, three desirable outputs, and one undesirable output were used for environmental efficiency, although the undesirable output was dropped from the data for operational efficiency measurement. In particular, we used a model that incorporated a framework of managerial disposability. The first priority of the model is the environmental efficiency and it can examine the existence of ecotechnology innovation by signs of dual variables. From the results, we arrived at the following three findings.

First, environmental efficiencies or EEV and EEC of EPCos were statistically invariant over the period 2003-2015, while operational efficiencies or OEV and OEC decreased in the same period. In particular, operational efficiencies decreased from 2010 to 2013 from the influence of Fukushima Daiichi nuclear power plant accident, although they recovered to some extent toward 2015. This trend implies that the Fukushima accident influenced EPCos'operational efficiency, but not their environmental efficiency. Second, Japanese EPCos undertook efforts to promote environmental protection using ecotechnology innovation to reduce $\mathrm{CO}_{2}$ emissions while keeping or increasing the level of production of desirable outputs. Third, Tokyo EPCo was the most 
TABLE 4: Kruskal-Wallis rank sum test.

\begin{tabular}{|c|c|c|c|c|c|c|}
\hline & EEV & EEC & SEE & OEV & OEC & SOE \\
\hline $\begin{array}{l}\text { Hypothesis } 1 \\
\text { Periods, d.f. }=12\end{array}$ & 7.854 & 4.934 & 5.646 & $34.794^{* * *}$ & $45.912^{* * *}$ & 13.78 \\
\hline $\begin{array}{l}\text { Hypothesis } 2 \\
\text { Companies, d.f. }=8\end{array}$ & $52.076^{* * *}$ & $49.201^{* * *}$ & $19.714^{* *}$ & $38.945^{* * *}$ & $21.47^{* * *}$ & $48.482^{* * *}$ \\
\hline
\end{tabular}

Note. The values represent chi-squared statistics with consideration of ties; d.f. means degrees of freedom. Symbols $* * *$ and $* *$ indicate statistical significance at the level of $1 \%$ and $5 \%$, respectively.

TABLe 5: Dual variables for desirable putputs.

\begin{tabular}{|c|c|c|c|c|c|c|c|c|c|}
\hline Year & Hokkaido & Tohoku & Tokyo & Chubu & Hokuriku & Kansai & Chugoku & Shikoku & Kyushu \\
\hline \multicolumn{10}{|c|}{ Total revenue } \\
\hline 2003 & -1.65 & 1.02 & -0.91 & 0.18 & 2.64 & 0.24 & -3.00 & 0.47 & -2.86 \\
\hline 2004 & -6.74 & 0.31 & -0.83 & -3.51 & -0.23 & -0.04 & -1.86 & 1.20 & -5.84 \\
\hline 2005 & -8.41 & 1.02 & -0.79 & -3.22 & -0.24 & -4.28 & -2.93 & 0.52 & -14.19 \\
\hline 2006 & -2.37 & 1.11 & 0.61 & -9.39 & -8.68 & -4.43 & -2.71 & 0.53 & -10.53 \\
\hline 2007 & -6.26 & 0.27 & 0.06 & -174.05 & -25.12 & -1.97 & -1.70 & 1.89 & -8.35 \\
\hline 2008 & 0.63 & -41.10 & 0.07 & 0.17 & 2.40 & -0.49 & 0.29 & 1.97 & -0.66 \\
\hline 2009 & -9.33 & 0.28 & -0.59 & -0.01 & 0.40 & -0.64 & -0.73 & 0.38 & -1.89 \\
\hline 2010 & -10.63 & 0.28 & -0.58 & -0.05 & -9.50 & -0.85 & -1.60 & 0.43 & -1.74 \\
\hline 2011 & 2.63 & -11.14 & 0.21 & -2.73 & -0.31 & -0.60 & 0.29 & 0.72 & -0.24 \\
\hline 2012 & -0.71 & 0.18 & -0.12 & -3.21 & -1.09 & -0.66 & 0.28 & 9.65 & -0.81 \\
\hline 2013 & -8.41 & 0.83 & 0.18 & -0.53 & -0.01 & 0.25 & 0.60 & 8.47 & 0.65 \\
\hline 2014 & 2.17 & 0.78 & 0.13 & -0.64 & -0.03 & 0.32 & 0.61 & 14.72 & 0.51 \\
\hline 2015 & 2.02 & 1.36 & -0.08 & 0.17 & 0.66 & 0.58 & 1.10 & 16.98 & 0.65 \\
\hline \multicolumn{10}{|c|}{ Total enterprise value } \\
\hline 2003 & -0.77 & 1.67 & 0.71 & 2.41 & 2.91 & -0.31 & 0.02 & 1.25 & -2.30 \\
\hline 2004 & 0.05 & -0.39 & 0.64 & 1.23 & 0.17 & -0.14 & -0.20 & 1.05 & -1.54 \\
\hline 2005 & -0.02 & 0.90 & 0.61 & 1.13 & 0.17 & 0.20 & 0.05 & 1.11 & -1.12 \\
\hline 2006 & -0.01 & 0.97 & 1.55 & 3.11 & 0.34 & 0.21 & 0.04 & 1.13 & 0.01 \\
\hline 2007 & 0.05 & -0.34 & 0.07 & -18.73 & 0.64 & 0.08 & -0.18 & 2.50 & 1.24 \\
\hline 2008 & -0.79 & -6.80 & 0.07 & -0.22 & 2.64 & -0.25 & -0.37 & 2.60 & -0.31 \\
\hline 2009 & -0.02 & -0.36 & -0.05 & -0.94 & 1.18 & -0.33 & -0.34 & 1.09 & -0.20 \\
\hline 2010 & -0.03 & -0.35 & -0.05 & -0.80 & -0.02 & -0.75 & -0.17 & 1.26 & -0.54 \\
\hline 2011 & -15.44 & -5.05 & 0.12 & -3.74 & -4.10 & -0.63 & -0.37 & -0.91 & -1.39 \\
\hline 2012 & -6.29 & -0.36 & -0.50 & -4.40 & -7.23 & -0.81 & -0.35 & -18.47 & -1.11 \\
\hline 2013 & 0.02 & 0.73 & 0.16 & -0.92 & -4.58 & 0.17 & 0.10 & 0.07 & 0.37 \\
\hline 2014 & 2.05 & 0.68 & 0.09 & -1.10 & -3.86 & 1.18 & 0.10 & -5.54 & 1.42 \\
\hline 2015 & 1.91 & 1.64 & -0.44 & -0.21 & -0.83 & 1.55 & 0.96 & -6.39 & 1.78 \\
\hline \multicolumn{10}{|c|}{ Total electricity sold } \\
\hline 2003 & 3.36 & -2.45 & 0.38 & -2.62 & -4.71 & 0.48 & 3.02 & -0.69 & -0.88 \\
\hline 2004 & 6.78 & 0.61 & 0.35 & 2.05 & -1.05 & 0.54 & 2.27 & -1.29 & 5.96 \\
\hline 2005 & 8.19 & -1.56 & 0.33 & 1.88 & -1.10 & 3.70 & 2.90 & -0.63 & 11.74 \\
\hline 2006 & 3.08 & -1.69 & -2.00 & 4.95 & 8.29 & 3.83 & 2.69 & -0.64 & 8.21 \\
\hline 2007 & 6.30 & 0.53 & 0.19 & 165.24 & 20.69 & 1.97 & 2.07 & -3.51 & 5.93 \\
\hline 2008 & 1.24 & -16.00 & 0.19 & 0.34 & -4.29 & 0.40 & 0.58 & -3.65 & 1.35 \\
\hline 2009 & 9.09 & 0.56 & 0.70 & 1.16 & -0.43 & 0.53 & 1.48 & -0.38 & 2.30 \\
\hline 2010 & 10.35 & 0.56 & 0.70 & 1.04 & 9.26 & 1.20 & 1.95 & -0.44 & 2.41 \\
\hline 2011 & 10.11 & 1.28 & -0.23 & 5.61 & 5.05 & 0.96 & 0.58 & 1.43 & 1.74 \\
\hline 2012 & 6.04 & 0.50 & 0.73 & 6.60 & 7.99 & 0.84 & 0.56 & 2.93 & 1.17 \\
\hline 2013 & -10.76 & -1.26 & -0.21 & 1.08 & 5.26 & -0.22 & -0.27 & -10.68 & -0.69 \\
\hline 2014 & -4.31 & -1.19 & -0.11 & 1.29 & 4.73 & -2.07 & -0.27 & -14.86 & -3.59 \\
\hline 2015 & -4.02 & -3.42 & 0.65 & 0.33 & 1.30 & -2.64 & -1.67 & -17.14 & -4.52 \\
\hline$\%$ of negative value & $51 \%$ & $41 \%$ & $38 \%$ & $51 \%$ & $51 \%$ & $49 \%$ & $44 \%$ & $38 \%$ & $56 \%$ \\
\hline
\end{tabular}


efficient among the nine incumbent EPCos for environmental and operational efficiencies under VRTS technology. The efficiency status of Tokyo EPCo did not change even after the Fukushima Daiichi nuclear power accident, because the damage to corporate value incurred by the accident was extended not only to Tokyo but also to the other EPCos and reduced their corporate values. This was probably caused by the industry-wide compensation scheme that allocates the compensation cost to the other EPCos. Hence, the decreased corporate enterprise value did not change the relative performance among EPCos, although their average efficiency, particularly operational efficiency, decreased over the period of this study. This type of similarity among the nine incumbent EPCos under uniform government regulation has been conventionally observed in Japan. On the other hand, as indicated by the results of the Kruskal-Wallis rank sum test, there are clear differences in operational and environmental efficiencies among EPCos. Such performance differences could become larger as time proceeds and market liberalization advances further.

This study has two remaining issues for future research. First, examination and decomposition of efficiency measures over the period give us further insight on operations of EPCos. We can use a framework of productivity index, such as the Malmquist index, for the extended study. Based on this index, we could decompose the productivity changes into factors that represent efficiency change and technology change. Second, we can investigate the relationship between capital investment and ecotechnology innovation measured in DEA. For this extension, detailed data on capital investment are necessary, but this would enhance the research capability of DEA for examining investment efficiency.

\section{Conflicts of Interest}

The authors declare that they have no conflicts of interest.

\section{Acknowledgments}

This work was financially supported by Japan Society for the Promotion of Science (JSPS) Grant-in-Aid for Scientific Research (KAKENHI) (26285050 and 16K01236).

\section{References}

[1] H. Leibenstain, "Allocative efficiency vs. X-efficiency," American Economic Review, vol. 56, no. 3, pp. 392-415, 1966.

[2] A. Charnes, W. W. Cooper, and E. Rhodes, "Measuring the efficiency of decision making units," European Journal of Operational Research, vol. 2, no. 6, pp. 429-444, 1978.

[3] A. Charnes, W. W. Cooper, B. Golany, L. Seiford, and J. Stutz, "Foundations of data envelopment analysis for ParetoKoopmans efficient empirical production functions," Journal of Econometrics, vol. 30, no. 1-2, pp. 91-107, 1985.

[4] W. W. Cooper, K. S. Park, and J. T. Pastor, "RAM: a range adjusted measure of inefficiency for use with additive models, and relations to other models and measures in DEA," Journal of Productivity Analysis, vol. 11, no. 1, pp. 5-42, 1999.
[5] K. Aida, W. W. Cooper, J. T. Pastor, and T. Sueyoshi, "Evaluating water supply services in Japan with RAM: a range-adjusted measure of inefficiency," Omega, vol. 26, no. 2, pp. 207-232, 1998.

[6] K. Tone, "A slacks-based measure of efficiency in data envelopment analysis," European Journal of Operational Research, vol. 130, no. 3, pp. 498-509, 2001.

[7] J. T. Pastor, J. L. Ruiz, and I. Sirvent, "Statistical test for detecting influential observations in DEA," European Journal of Operational Research, vol. 115, no. 3, pp. 542-554, 1999.

[8] T. Sueyoshi and K. Sekitani, "Computational strategy for Russell measure in DEA: second-order cone programming," European Journal of Operational Research, vol. 180, no. 1, pp. 459-471, 2007.

[9] J. Ji and Y. Wang, "Commercial bank efficiency evaluation in consideration of the undesirable output and its link with stakeholders relationship: an application of China's commercial banks," Mathematical Problems in Engineering, vol. 2014, Article ID 949717, 7 pages, 2014.

[10] J. Chen, Z. Wan, F. Zhang, N.-K. Park, X. He, and W. Yin, "Operational efficiency evaluation of iron ore logistics at the ports of Bohai Bay in China: based on the PCA-DEA Model," Mathematical Problems in Engineering, vol. 2016, Article ID 9604819, 13 pages, 2016.

[11] J.-M. Wang, X.-J. Ge, L.-L. Zhang, and H. Zhang, "Management index systems and energy efficiency diagnosis model for power plant: cases in China," Mathematical Problems in Engineering, vol. 2016, Article ID 8159871, 13 pages, 2016.

[12] T. Sueyoshi and D. Wang, "Measuring scale efficiency and returns to scale on large commercial rooftop photovoltaic systems in California," Energy Economics, vol. 65, pp. 389-398, 2017.

[13] Q. Wang and C.-X. Geng, "Research on financing efficiencies of strategic emerging listed companies by six-stage DEA model," Mathematical Problems in Engineering, vol. 2017, Article ID 3284657, 8 pages, 2017.

[14] T. Sueyoshi, Y. Yuan, and M. Goto, "A literature study for DEA applied to energy and environment," Energy Economics, vol. 62, pp. 104-124, 2017.

[15] M. V. P. Souza, M. Diallo, R. C. Souza, and T. K. N. Baidya, "The cost efficiency of the brazilian electricity distribution utilities: a comparison of bayesian SFA and DEA models," Mathematical Problems in Engineering, vol. 2010, Article ID 593059, 20 pages, 2010.

[16] C.-N. Wang, L.-C. Lin, and D. Murugesan, "Analyzing PSU's performance: A case from ministry of petroleum and natural gas of India," Mathematical Problems in Engineering, vol. 2013, Article ID 802690, 9 pages, 2013.

[17] X. Han, X. Xue, J. Ge, H. Wu, and C. Su, "Measuring the productivity of energy consumption of major industries in China: a DEA-based method," Mathematical Problems in Engineering, vol. 2014, Article ID 121804, 12 pages, 2014.

[18] G. Bi, P. Wang, F. Yang, and L. Liang, "Energy and environmental efficiency of china's transportation sector: a multidirectional analysis approach," Mathematical Problems in Engineering, vol. 2014, Article ID 539596, 12 pages, 2014.

[19] D. D. Wang and T. Sueyoshi, "Assessment of large commercial rooftop photovoltaic system installations: Evidence from California," Applied Energy, vol. 188, pp. 45-55, 2017.

[20] T. Sueyoshi and M. Goto, "Undesirable congestion under natural disposability and desirable congestion under managerial disposability in U.S. electric power industry measured by DEA 
environmental assessment," Energy Economics, vol. 55, pp. 173188, 2016.

[21] R. Färe, S. Grosskopf, C. A. K. Lovell, and C. Pasurka, "Multilateral productivity comparisons when some outputs are undesirable: a nonparametric approach," Review of Economics and Statistics, vol. 71, no. 1, pp. 90-98, 1989.

[22] T. Sueyoshi and M. Goto, "Environmental assessment by DEA radial measurement: U.S. coal-fired power plants in ISO (Independent System Operator) and RTO (Regional Transmission Organization)," Energy Economics, vol. 34, no. 3, pp. 663-676, 2012.

[23] T. Sueyoshi and D. Wang, "Radial and non-radial approaches for environmental assessment by Data Envelopment Analysis: Corporate sustainability and effective investment for technology innovation," Energy Economics, vol. 45, pp. 537-551, 2014.

[24] T. Sueyoshi and Y. Yuan, "Marginal Rate of Transformation and Rate of Substitution measured by DEA environmental assessment: Comparison among European and North American nations," Energy Economics, vol. 56, pp. 270-287, 2016a.

[25] T. Sueyoshi and Y. Yuan, "Returns to damage under undesirable congestion and damages to return under desirable congestion measured by DEA environmental assessment with multiplier restriction: Economic and energy planning for social sustainability in China," Energy Economics, vol. 56, pp. 288-309, 2016 b.

[26] M. Goto and T. Sueyoshi, "Electricity market reform in Japan after Fukushima," Economics of Energy \& Environmental Policy, vol. 5, no. 1, pp. 15-30, 2016. 


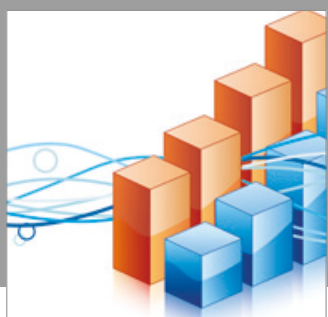

Advances in

Operations Research

vatersals

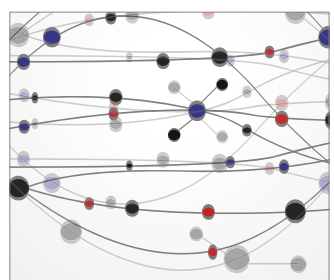

\section{The Scientific} World Journal
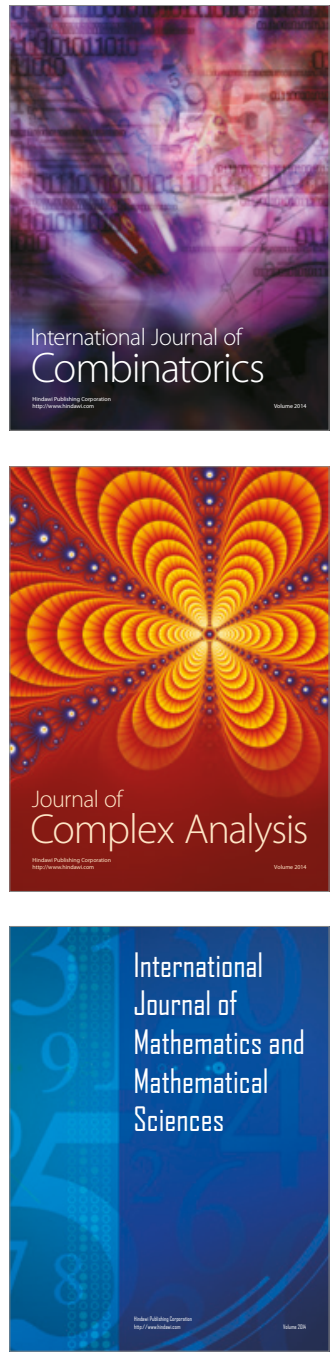
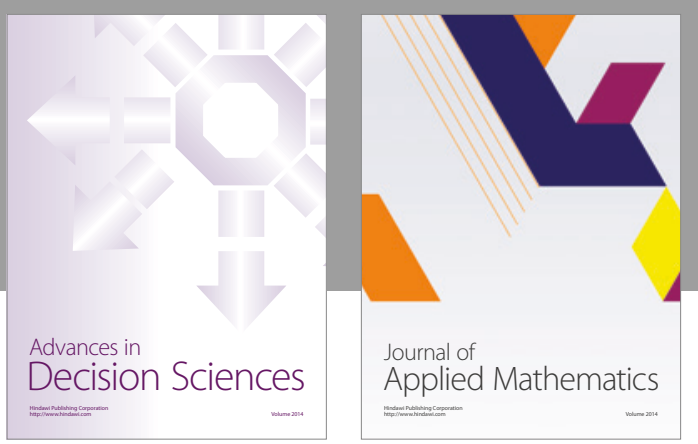

Algebra

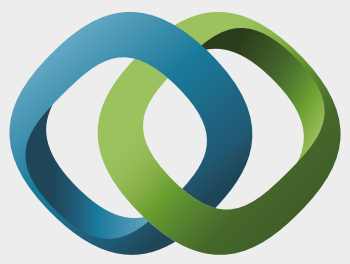

\section{Hindawi}

Submit your manuscripts at

https://www.hindawi.com
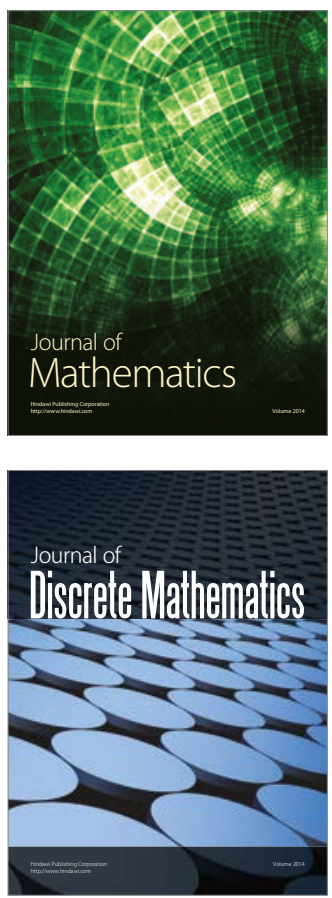

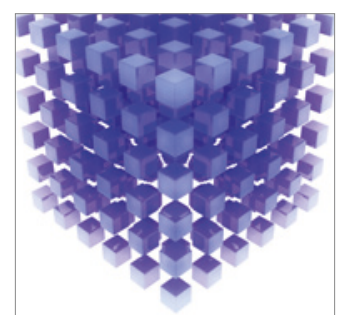

Mathematical Problems in Engineering
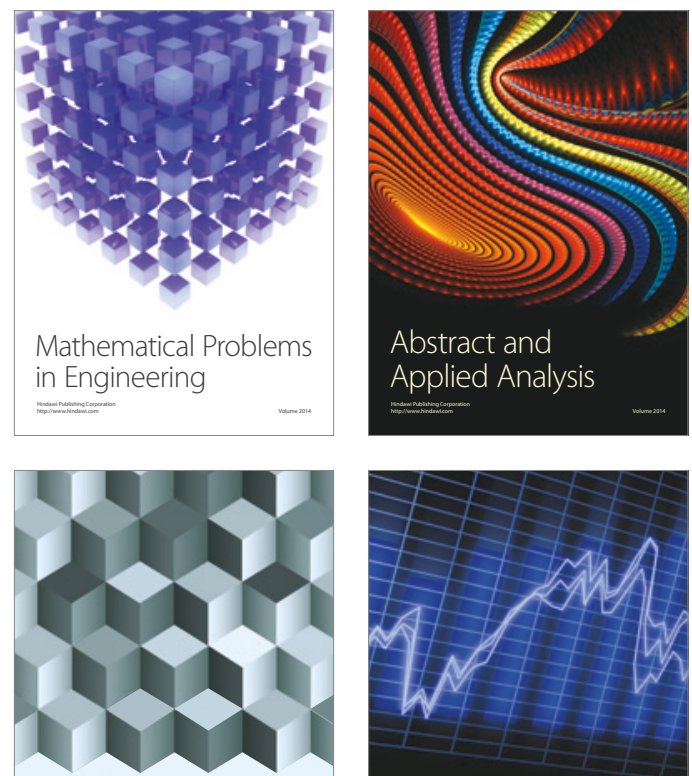

Journal of

Function Spaces

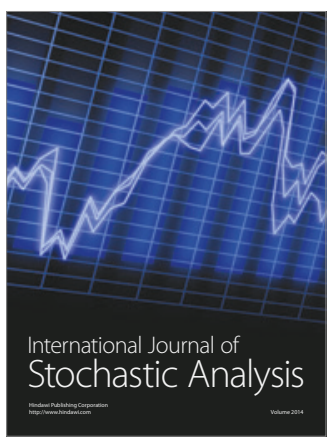

Probability and Statistics
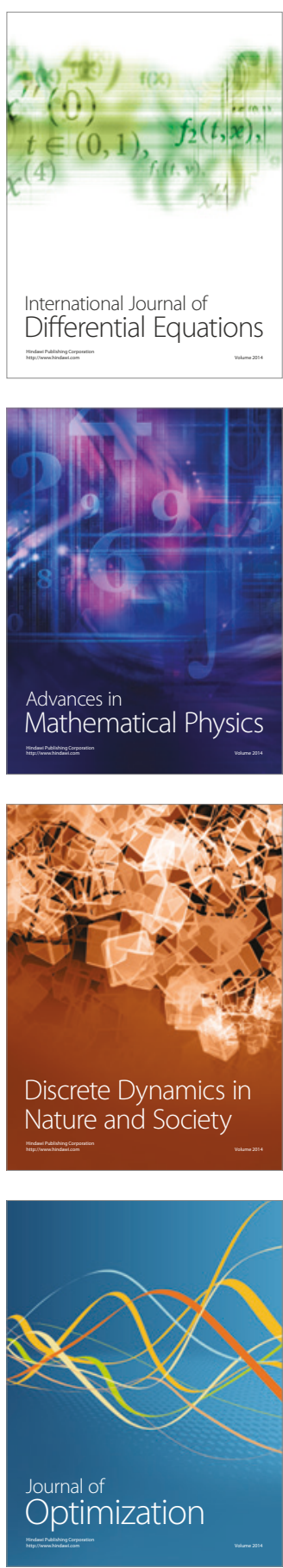